\title{
El japonismo de Star Wars
}

\author{
ANTONIO MÍGUEZ SANTA CRUZ \\ Universidad de Córdoba (España)
}

\begin{abstract}
Resumen
El universo de Star Wars es tan popular que prácticamente se ha estudiado desde todas las perspectivas posibles. Sin embargo, la enorme cantidad de referencias visuales o filosóficas que conviven escondidas tras los atrezzos, los vestuarios, o el mismo guion de George Lucas, nos parece una asignatura pendiente a la hora de comprender completamente la profundidad de la afamada saga galáctica.

En este caso, nosotros nos ocuparemos de comprobar hasta qué punto existe el japonismo en Star Wars, analizando las influencias o códigos procedentes del país del sol naciente más allá del obvio caso del yelmo de Darth Vader. Así pues, ¿tuvo tanta influencia La fortaleza escondida de Kurosawa en su concepción?; ¿son los jedi un trasunto de los guerreros samurái? O ¿son la Fuerza y el budismo más semejantes de lo que a priori podríamos creer? Sobre esas y otras muchas cuestiones girarán las siguientes páginas.
\end{abstract}

Palabras clave: Influencia, Chambara, Samurái, Budismo, Asura.

Star Wars Japonism

\begin{abstract}
Nowadays, The Star Wars saga is so popular that it has been studied from every possible perspective. However, the enormous amount of visual or philosophical references to be unraveled that coexist hidden behind the props, costumes, or the proper George Lucas script, it seems to us a pending subject if we want to fully understand the depth of the famous galactic saga. In this case, we will see how Japan is present in Star Wars analyzing the influences or codes coming from "the land of the Rising sun" beyond the obvious case of Darth Vader's helmet. Therefore, several questions can be made, such as : Was Kurosawa's hidden fortress so important in his conception? Are the Jedi in a certain way a representation of the Samurai warriors? or, are Force and Buddhism more similar than we might think at first? So, these and many other issues will be dealt with in the following pages.
\end{abstract}

Keywords: Influence, Chambara, Samurai, Buddhism, Asura. 


\section{Star Wars en las convenciones de manga y cultura japonesa}

Los festivales que giran en torno al manganime o la cultura japonesa tienden cada vez más a incluir temáticas ajenas a la japofilia. En la actualidad no es extraño cruzarse en los Salones del Manga y Cultura japonesa con cosplayers ataviados de Dragon Ball, Caballeros del Zodiaco y Naruto, entremezclándose con Iron Man o tal vez algún personaje de Super Mario Bros. El culmen lo representan eventos como la FicZone, donde se opta por suprimir del título de la franquicia cualquier tipo de alusión al país del sol naciente pese a que este siga siendo el protagonista indiscutible del programa.

Como el lector podrá imaginarse, el cine, siendo la plataforma narrativa con más capacidad de penetración popular, también se ha sumado a este fenómeno múltiple e imbricado, en el que los aficionados parten de un gusto específico, pero no tardan en desarrollar interés por otras ramas del ocio contemporáneo ${ }^{1}$. Al hilo de lo anterior, si nos detuviéramos en el entretenimiento audiovisual más allá de lo estrictamente asiático o el subgénero supers ${ }^{2}$, cuatro son las sagas predominantes en este tipo de convenciones, a saber: El Señor de los Anillos, Juego de Tronos, Harry Potter y sobre todas las demás, Star Wars. Lo paradójico e interesante del último caso es que, el azar, ayudado por la sensibilidad de un gran sector del público, ha convenido en reunir bajo los mismos espacios dos hitos fundamentales de la cultura geek: La guerra de las galaxias y Japón. A lo largo de las páginas siguientes comprobaremos cómo estas tendencias disponen de muchísimos más elementos en común que el archiconocido caso del yelmo de Darth Vader.

\section{Star Wars y la Fortaleza escondida de Kurosawa}

Desde la llegada del cinematógrafo a Japón se explotó el jidaigeki, o cine de época, por diversas razones. Aquí hemos de recordar que el país a finales del siglo XIX apenas había superado el régimen feudal de Tokugawa ${ }^{3}$ y, por tanto, seguía conservando infinidad de infraestructuras en las que recrear aquellas ficciones. Por si fuera poco, aún disponían del $\mathrm{kabuki}^{4}$ —entre otras artes escénicas - casi siempre inspiradas en el periodo de los samuráis; este punto es de relevancia estructural porque a diferencia de como ocurre en occidente el cine japonés evoluciona a partir del teatro y no de la fotografía. El hecho de que los primeros films se tratasen en la práctica de kabuki filmado marcó una inclinación natural hacia el género histórico, que poco a poco fue ganando en complejidad y diversificándose en diversos subgéneros de los cuales el más exitoso fue el chambara ${ }^{5}$.

Antes de finalizar la Segunda Guerra Mundial el tono de estos films era más complejo, rayando incluso el experimentalismo en casos como Jûjiro (Teinosuke

\footnotetext{
${ }^{1}$ Borrego Patrón, S. Hernández Suarez, C. "Capitalización y crisis en los salones del Manga. Organización y expansión de la cultura Otaku en Andalucía”. En Gómez Aragón, A. (Coord.), Japón y Occidente, el patrimonio cultural como punto de encuentro. AEJE. 2016. Sevilla. pp. 321-328.

${ }^{2}$ Se refiere a los cómics o películas cuyos protagonistas son superhéroes.

3 Tercera de las dictaduras militares que se dieron en Japón (1600/1615-1868). El régimen de los Tokugawa es especialmente relevante porque además supuso un periodo de aislamiento forzado que ayudó a fraguar muchos de los aspectos esenciales del ciudadano japonés actual.

${ }^{4}$ Arte escénica japonesa que alcanzó su esplendor durante el periodo Edo (Tokugawa). Consistía en un espectáculo que mezclaba el canto, el baile y otra serie de aptitudes, destinado principalmente al emergente público urbano. Por tanto, su naturaleza era más popular y menos solemne que el aristocrático noh.

${ }^{5}$ Subgénero del jidaigeki de clara tendencia a la acción, generalmente de no demasiado presupuesto y claras analogías con el spaguetti western europeo. Su nombre, chambara, proviene de la mezcla de las onomatopeyas chan chan — dos espadas al chocar-y bara bara —el sonido del corte de la carne y su caída al suelo.
} 
Kinugasa, Jûjiro, 1928) o explotando la solemnidad de la épica japonesa con Los cuarenta y siete samuráis (Kenji Mizoguchi, Genroku chushingura, 1941). A partir de la década de 50's, una vez los estadounidenses levantaran la proscripción a las historias de corte militarista, el chambara empezó a proliferar de una manera más ligera e irreflexiva si hablamos narrativamente, pero brillante y fresca en otra gran multitud de aspectos. Preludio de lo que supondría el spaghetti western respecto al cine de vaqueros americano una década más tarde, aquí firmaron títulos con letras de filigrana Hiroshi Inagaki con Samurai (1954), Tokuzô Tanaka con Los somnolientos ojos de la muerte (1963), o incluso el subversivo Kihachi Okamoto, con La espada del mal (1966).

El conocido como menos japonés de los directores japoneses, Akira Kurosawa - falacia que a base de repetirse muchos asumen como real - fue desde luego básico para relanzar internacionalmente el cine de bushis gracias sobre todo a Los siete samuráis (1954) ${ }^{6}$. Inoculado ya el gusto por los guerreros nipones en todo Occidente, llegarían las reescrituras de Shakespeare, Trono de Sangre (Kumonosu-jô, 1957) y Ran (Ran, 1985), lo que no hizo sino incrementar el alcance del fenómeno ${ }^{7}$. Ahora bien, si existe una obra del director tokiota relacionada hasta la extenuación con Star Wars, esa es sin duda La fortaleza escondida (Kakushi Toride no San-Akunin, 1958), de la cual se ha dicho en multitud de foros que sirvió de inspiración a George Lucas a la hora de concebir su afamada Space Opera, cuando no se sostiene directamente que las aventuras de Luke Skywalker y la princesa Leia eran un remake velado de aquella.

Mediante un análisis del resumen completo del filme vamos a intentar dilucidar si lo anterior es cierto o no lo es.

La fortaleza escondida comienza con dos granjeros, Tahei y Matashichi interpretados por Minoru Chiaki y Kamatari Fujiwara respectivamente - llegando a una explanada en la que había tenido lugar una de las múltiples batallas habidas durante el sengoku jidai. Los personajes fueron retenidos contra su voluntad por el bando vencedor, viéndose obligados a enterrar los muertos de ambos ejércitos. Luego de separarse por ciertas desavenencias, los protagonistas son nuevamente capturados y forzados a drenar las aguas de los aledaños de un enorme castillo, donde al parecer el derrotado clan Akizuki ocultó un tesoro de valor incalculable.

En ese instante sucede una insurrección de los prisioneros aprovechada por Tahei y Matashichi para escapar y llegar hasta un río en el que encuentran oro marcado por el kamon $^{8}$ del clan Akizuki. A partir de entonces, la pareja viaja junto al comandante del bando derrotado, Makabe Rokurōta - Toshiro Mifune - que a su vez escolta a la princesa Yuki Akizuki - Misa Uehara - y lo que queda del oro blasonado de su familia. Buscando mantener en secreto la identidad de Yuki durante la huida, el general Makabe consigue que la dama simulara ser muda. Durante su periplo, los campesinos tratan de apoderarse del metal precioso en diversas ocasiones, rasgo que evidencia sus características de antihéroes ${ }^{9}$.

A lo largo del último tercio de la narración el excéntrico grupo es encarcelado por el comandante de Yamana. No obstante, en un giro de los acontecimientos, el antagonista los deja escapar en agradecimiento a Rokurōta, quien anteriormente le perdonó la vida durante el desarrollo de un combate singular. Ya en pleno desenlace, Tahei y Matashichi consiguen hacerse con el tan ansiado oro, aunque poco después

\footnotetext{
${ }^{6}$ Ritchie, D. The Films of Akira Kurosawa. California University Press.1996. Los Ángeles. p. 97.

${ }^{7}$ Navarro, A.J. Los samuráis en el cine de Akira Kurosawa. Nosferatu. Revista de Cine. № 44, 2003. pp. 29-45.

${ }^{8}$ Signo identificativo perteneciente a una familia, clan, ejército o personaje eminente. Aunque en esencia comparable a nuestra heráldica europea, lo cierto es que alberga las suficientes diferencias respecto a esta como para considerarlo un lenguaje distinto.

${ }^{9}$ Freixas, R. La Fortaleza escondida. Dirigido por ...revista de cine. №. 343, 2005. pp. 37-38.
} 
fueron descubiertos por los hombres de Akizuki. Entonces, el general Makabe los llevó a palacio para explicarles quién era en realidad Yuki, al tiempo que se les aclaró que aquel oro servía al fin de restaurar el dominio de su familia en casos de necesidad. De una forma u otra, a Tahei y Matashichi se les concede un ryō en gratitud por los servicios prestados, por mucho que su comportamiento distara tanto de la ejemplaridad.

Visto lo anterior, disponemos de varios intertextos que enlazarían esta película y La guerra de las galaxias:

El primero de ellos son las analogías entre los campesinos protagonistas y los dos androides, quienes ejercen de contrapunto cómico en ambas ficciones, además de compartir fisionomías similares. Reconocida la influencia por el mismo George Lucas como veremos poco después, nosotros apuntaremos al distinto trasfondo de los personajes para diluir un poco el impacto de tal afirmación. Al punto, hablamos de protagonistas dotados de una alineación moral censurable en el caso de Kurosawa y de secundarios que demuestran una conducta casi modélica — están programados para ello — si nos referimos a Lucas.

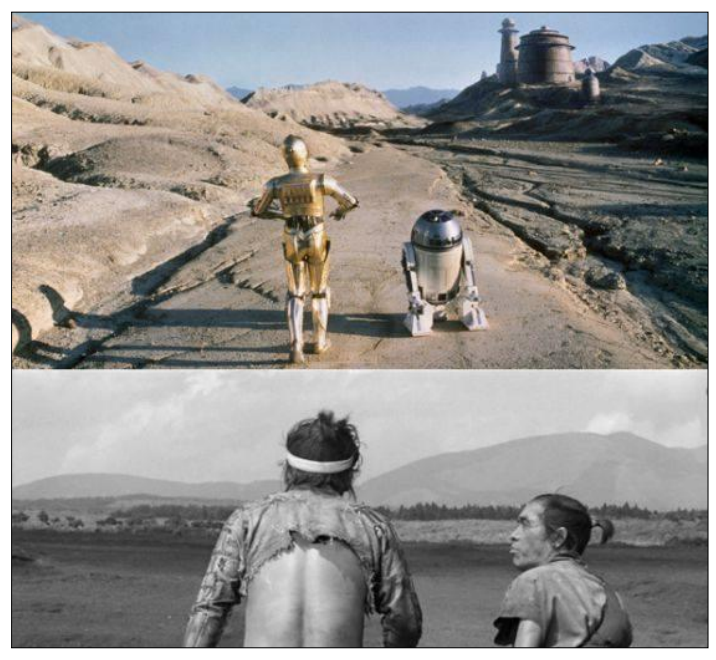

De hecho, existe una escena donde Tahei y Matashichi se quedan en compañía de la princesa Yuki mientras ella dormía. Entonces, se sucede un plano de la mujer en el suelo dejando a la vista sus piernas desnudas, situación que desata hasta tal punto las bajas pasiones de los agricultores que incluso hacen ademán de violarla. Si añadimos aquí el trazo grueso de su humor - muy deudor del teatral chori $^{10}$ - o su gran componente picaresco, relativizaremos las semejanzas conceptuales que pesan sobre ambas parejas ${ }^{11}$.

Por otra parte, disponemos de un par de princesas que intentan escapar a su vez de dos ejércitos de conquista. Este punto es demasiado laxo y superficial según nuestra perspectiva, pues no podemos establecer paralelismos evidentes si dejamos a un lado el sexo y el título de sendas mujeres. Analicemos, en este sentido, el carácter de las dos protagonistas; Yuki, por ejemplo, es díscola, incontrolable, poco madura y difícil de convencer. Sin duda estamos ante un perfil muy llamativo para la mujer cinematográfica en el Japón de la época ${ }^{12}$, y he aquí donde reside su principal valor hermenéutico. Leía, por el contrario, es más vital o determinante en un sentido activo, capaz de cualquier hazaña en búsqueda de derrocar al imperio galáctico, y por supuesto, dotada de un mayor equilibrio emocional o capacidad de liderazgo.

Otro elemento de mucho menos peso es la redención de los antagonistas principales - Tadokoro y Vader-, quienes deciden pasar al bando de los buenos en una decisión esencial para el desenlace de sus respectivas aventuras. Pese a ello, se cuentan por centenas las ficciones con villanos que, por diversas circunstancias, se redimen más tarde o temprano. En especial recurrente es el factor dentro del

\footnotetext{
${ }^{10}$ Personaje de corte cómico perteneciente a algunas artes escénicas japonesas como el bunraku.

${ }^{11}$ Ortilani, B. The japanese Teatre: from shamanistic to the contemporary pluralism. Princetown University Press. 1990. Nueva Jersey. p. 276.

${ }^{12}$ Míguez Santa Cruz, A. El fantasma en el cine japonés de posguerra. De rasgo folclórico a icono feminista. Servicio de publicaciones de la Universidad de Córdoba. 2016. Córdoba. p. 32.
} 
manganime, con casos tan célebres como Piccolo o Vegeta en Dragon Ball; Ikki de Fénix en Saint Seiya; Orochimaru en Naruto Shippuden; o Renji Abarai en Bleach.

Visto lo cual, ninguna semejanza entre la reconocidísima saga galáctica y el film japonés es absoluta o irrefutable, salvo la pequeña concesión que el propio George Lucas concede en el caso de los androides C-3PO y R2-D2, quienes sí estuvieron inspirados sin ambages en Tahei y Matashichi. Veamos esta entrevista concedida para la TV aprovechando el estreno del Episodio I:

En realidad, "La fortaleza escondida" no está entre mis películas favoritas de Kurosawa, aunque me parezca visualmente impresionante... algo que sí me influyó de "La Fortaleza escondida" cuando estaba escribiendo Star Wars fue el hecho de que la historia estuviera narrada desde el punto de vista de los dos personajes más insignificantes del relato — los campesinos —. Quise usar el mismo recurso incluyendo la participación de los dos androides y creo que en realidad esta es la única influencia de peso que Star Wars tiene de "La fortaleza escondida". El hecho de que hubiera una princesa intentando escapar de las líneas enemigas y algún que otro elemento más pienso que es más coincidencia que otra cosa. Además, creo que el contexto militar del Japón de la época y la coyuntura política de Star Wars no guardan ninguna relación... ${ }^{13}$

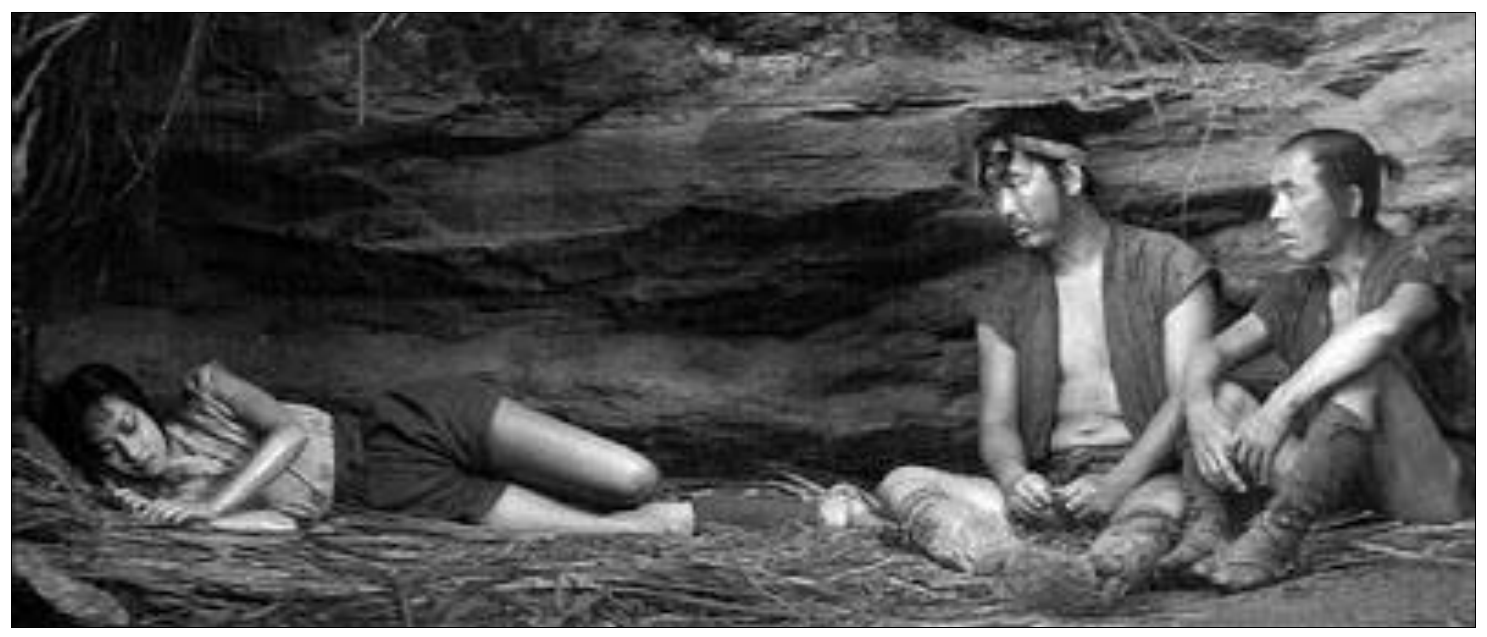

Si prestamos atención a los últimos asertos del productor californiano, situar el origen de las aventuras de los jedi en este film de Kurosawa no es que sea ya un juicio apresurado, sino más bien del todo erróneo. Pero ¿quiere esto decir que no existe el japonismo en Star Wars? Absolutamente, no. Aunque quizá sea aconsejable derribar el mito que gira en torno a Kakushi Toride no San-Akunin, para ampliar las miras hasta contemplar un género entero, el chambara, como culpable de la influencia.

\section{El japonismo de Star Wars}

A falta de un estreno más potente, Rogue One: Una historia de Star Wars (Gareth Edwards, 2016) monopolizó las carteleras durante el mercado navideño de aquel año, ejerciendo el rol que tiempo atrás ocuparan El Señor de los Anillos, algunos episodios de Harry Potter o, más recientemente, el mismo Hobbit. Pareciéndonos desde luego una de las entregas más pobres de la afamada saga galáctica, es cierto que

\footnotetext{
${ }^{13}$ Traducción propia. En: https://www.youtube.com/watch?v=TEJ6CzG9zVc\&t=5s (Consultado 20/12/2017).
} 
justifica una de las mayores lagunas en su guion, como es la total vulnerabilidad estructural del arma definitiva de las fuerzas imperiales: la Estrella de la Muerte. Así que, en el peor de los casos, su existencia dentro de la saga está ampliamente justificada.

De cualquier modo, ha sido Chirrut Îmwe, aquel místico invidente encarnado por el artista marcial Donnie Yen, quien verdaderamente nos impulsó a escribir este artículo. Si el lector recuerda, Îmwe repetía de manera constante el siguiente mantra:

\section{... La Fuerza está conmigo, yo soy uno con la Fuerza... La Fuerza está conmigo, yo soy uno con la Fuerza...}

Ello, unido al evidentísimo aspecto de monje budista que presenta el personaje, no puede dejar de conducirnos mentalmente al conocido como nembutsu, evocación constante de la creencia en Amida Buda practicada por los creyentes del Jōdo Shinshū, sub-escuela de la rama budista de la Tierra Pura ${ }^{14}$.

También llamada secta shinran por su creador, Shinran Shonin (1173-1263) $)^{15}$, alcanzó un rápido éxito entre los fideístas porque garantizaba la transmigración a un mundo mejor con tan solo verbalizar la frase Namu-Amida-Butsu, que vendría a significar algo así como confío en el Buda de la Vida y la Luz sin límites. Se puede apreciar claramente, aquí el trasfondo intelectual típico del budismo ortodoxo da un paso atrás en aras de la fe sin paliativos, de forma semejante a como ocurriría con cualquier jedi, conocedor absoluto de la Fuerza y sus entresijos, y el mismo Chirrut Îmwe, un semi-jedi que confiaba ciegamente en ella, pero sin llegar a hacerla suya o siquiera comprenderla en ningún caso.

Pero esta no es la primera vez que se estrechan vínculos entre el budismo y los personajes de Star Wars, siendo de hecho una dinámica notoria y asentada desde la misma Amenaza fantasma. Si echamos una vista atrás, relacionaréis rápidamente al maestro Qui-Gon Jinn con la sabiduría, la serenidad, la rectitud o el recogimiento, todos ellos elementos en consonancia con el budismo zen tan típico de la casta samurái.

Lo anterior es fácilmente comprobable al revisar el maltratado «Episodio I», aunque alcanza sus máximas cotas de visibilidad durante el épico combate final entre Qui-Gon y Darth Maul. Justo cuando ambos contrincantes quedan separados entre las puertas láser, Qui Gon decidió aprovechar aquel inesperado paréntesis para meditar, mientras que el sith optó por escrutarlo desafiante a través de la transparencia roja, caminando de un lado hacia el otro, como si de un león enjaulado se tratase. He aquí el equilibrio y el control frente al instinto y la expansión ${ }^{16}$.

En realidad, todos los lores tenebrosos de Star Wars representan el antónimo budista, ya que evaden la conquista de la perfección moral o el desapego de todo lo terreno para abrazar el poder mediante la vía más corta: la crueldad, la ira o el odio. Recordemos el peaje a pagar por las criaturas en exceso iracundas según la cosmovisión dhármica ${ }^{17}$, que no es otro sino una reencarnación adversa en forma de Asura ${ }^{18}$, deidad poderosísima pero alejada de la iluminación, además de sufrir prolongadas estancias en diversos planos desfavorables.

\footnotetext{
${ }^{14}$ Cornu, P. Diccionario del Budismo. Akal. Madrid. 2004. p. 528.

${ }^{15}$ Hasegawa, T. The life and thougth os Shinran Shonin. Shinsu Center of America. 2015. Los Ángeles. p 11.

${ }^{16}$ Martínez Rico, E. La guerra de las galaxias. El mito renovado. Imágica Ediciones. Toledo. 2015. pag. 99.

${ }^{17}$ Ramirez Serrano, G. El Budismo como respuesta al sufrimiento. Revista Temas: Departamento de Humanidades Universidad Santo Tomás Bucaramanga. Nº 1. 2007. pp. 135-142.

${ }^{18}$ Conocido como uno de los cuatro tipos de reencarnaciones perjudiciales, junto a la de animal, el de los narakas y el de los pretas.
} 


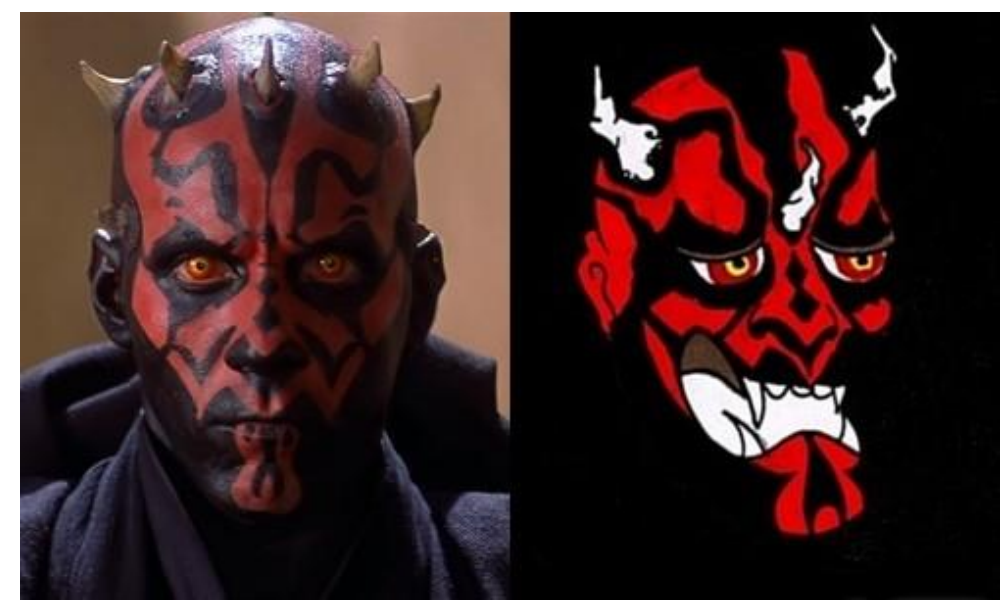

Por consiguiente, los sith y este tipo de demonios albergarían ciertas semejanzas. Respecto al sufrimiento, el miedo, o el odio, el maestro Yoda instruyó a Anakin en un diálogo muy esclarecedor para comprender las semejanzas entre la Fuerza y algunas ramas del budismo hacia el primer tercio de Star Wars: Episodio III. La venganza de los Sith. Veámoslo:

-Yoda: Muy cuidadoso debes ser al percibir el futuro, Anakin... El miedo a la pérdida un camino hacia el lado oscuro es. La muerte una parte natural de la vida es. Regocíjate por los que te rodean y que en la Fuerza se transforman, llorarlos no debes, añorarlos tampoco... El apego a los celos conduce. La negra sombra de la codicia es.

-Anakin: ¿Qué debo hacer, maestro Yoda, para liberarme del sufrimiento?

—Yoda: Aprender a liberarte de aquello que precisamente perder temes.

Es decir, la transformación de Anakin en Darth Vader se debió a su total embriaguez pasional, a su incapacidad para dominar su enfermizo amor por Padme, por su envidia tanto a Obi Wan como al resto del Consejo Jedi, o al odio desbocado surgido a raíz de la muerte de su madre a mano de los tuskens. La Fuerza es simétrica, induce a la armonía del mundo y comprenderla conlleva la responsabilidad de saber encauzarla. Y cómo no caer en la tentación del desenfreno manejando tal poder. La respuesta la da el mismo Yoda cuando insta a aislarse de todo lo sensorial, de aquello capaz de desviar al individuo de su fin último: ser uno con la Fuerza en el caso de los jedi, y alcanzar el despertar para el budista ${ }^{19}$.

Además, si los jedis comulgan con una creencia comparable al zen, es coherente pensar que también presenten similitudes con los creyentes más populares de aquella religión, léase, los samuráis. Si echamos un ojo a los siete preceptos del bushido ${ }^{20}$ sin saber qué estamos leyendo, podríamos pensar fácilmente que nos hallamos ante un código jedi. Es más, pienso que el carácter sincero, altruista y noble de los caballeros galácticos bebe directamente no ya del samurái mismo, sino de la heroica idealización occidental que de ellos se tiene, sin duda legado del cine, la literatura y, en definitiva, toda la mitografía circundante ${ }^{21}$.

\footnotetext{
${ }^{19}$ Bustamante, J.J. El despertar y la felicidad en el budismo. Polis. Revista latinoamericana. N $^{\circ}$ 8. 2004. pp. 1-10.

${ }^{20}$ Literalmente camino del guerrero (武士道), en realidad consiste en un código ético y de honor que sobre el papel regía el comportamiento de los samuráis. A pesar de que su mensaje sea más o menos objetivo, su lectura depende directamente del periodo histórico, llegando incluso a malinterpretarse en esencia durante momentos extremadamente militaristas, como es ejemplo la primera parte de showa jidai (1926-1945).

${ }^{21}$ Plou, C. Bajo los cerezos en flor. 50 películas para conocer Japón. Ed. UOC. Barcelona. 2017. p. 49.
} 
Según el universo de Star Wars, los guerreros jedi practican siete tipos diferentes de esgrima, estando algunos de ellos íntimamente relacionados con las artes marciales asiáticas $^{22}$. Por ejemplo, Darth Maul explotaba una espectacular mezcla entre wushu y capoeria en contraste con los duelos menos dinámicos de la primera trilogía, de alguna forma más proclive al del kendō japonés. Así pues, las precuelas supusieron un incremento en la espectacularidad de los combates gracias a la introducción de elementos propios del kung fu o la esgrima española, aunque se mantuvieron posturas de apresto tradicionalmente japonesas ya vistas en los episodios intermedios.

Virando hacia la indumentaria, también es reconocible el parentesco entre samuráis y jedis sin contar la obvia relación entre el yelmo de Darth Vader y el kabuto nipón. Por ejemplo, los chalecos con hombreras que en ocasiones visten personajes como Luke Skywalker o Anakin recuerdan al kataginu, prenda superior del conjunto llamado kamishimo. Otros miembros de la orden como Windu portan una especie de batas finas de color parduzco que asumen la función del haori, un amplio sobretodo concebido para lucirlo encima del popular kimono.

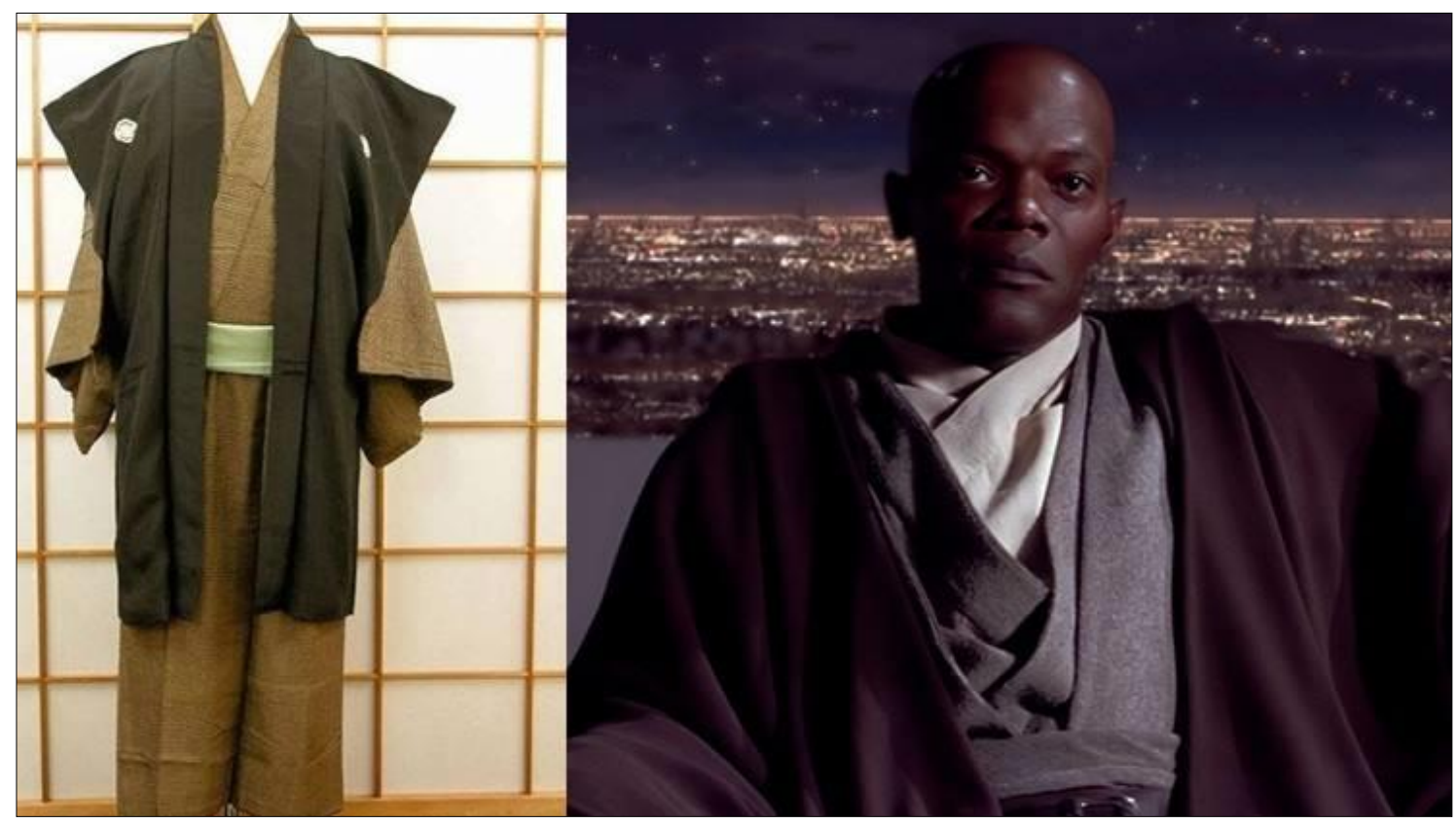

Más relevante aún es la semejanza conceptual entre el sable de luz y la katana o nihonto. Para sus portadores, ambas armas constituyen algo mucho más profundo que un mero instrumento de ataque o defensa, llegando a ser en la práctica otro apéndice del propio cuerpo y base fundamental para el crecimiento espiritual ${ }^{23}$. No descubrimos nada nuevo; Ieyasu Tokugawa ya pregonó que el alma del samurái era la katana, y como es natural, nadie no perteneciente a la casta buke podía blandirla sin incurrir en delito. Hablamos, por consiguiente, del icono innegociable de toda una élite. Lo mismo ocurría con el sable de luz, del que Obi Wan diría que:

... es el arma por antonomasia de un caballero jedi. No es grosera como un bláster y requiere más habilidad que solo la vista para usarse. Se trata de un arma elegante. También es un símbolo. Cualquiera puede usar un bláster o un

\footnotetext{
22 Wolf. R. O Dharma das armas. Origem e significados da iconografía marcial encontrada no budismo. Revista de estudos da Religiao. Vol. 13. № 2. 2013. pp. 101-117.

${ }^{23}$ Sala Ivars, M. Los sables japoneses y sus complementos. Revista de Museología. № 65. 2016. pp. 54- 66.
} 
cortador de fusión... pero usar bien un sable de luz es la marca de alguien extraordinario...

Nótese la contraposición entre la nobleza inmanente a la espada de luz y el descrédito deslizado hacia el arma a distancia, dicotomía extrapolable al shock sufrido por los orgullosos bushi ante la llegada del arcabuz portugués a mediados del s. XVI. Y es que tanto el bláster como el fusil eran considerados por la élite guerrera objetos deshonrosos e impíos, ya que permitían a soldados mediocres derrotar en combate a otros con mejor preparación y mayores méritos.

$\mathrm{Si}$ a todo lo precedente añadimos la analogía entre el recogido y maquillaje de las geishas con algunos looks presentados por la reina Amidala, obtendremos una space opera donde los héroes visten con kataginu y blanden catanas de luz, los villanos lucen yelmos samurái y las jefas de Estado insinúan el mundo flotante de Gion o Yoshiwara.

\section{Cerrando el círculo}

La Guerra de las Galaxias se compone de multitud de alusiones cinematográficas, literarias, religiosas, mitográficas e históricas. El gran logro de Lucas fue naturalizar dichas inspiraciones hasta el punto de que el gran público ni las llega a decodificar como referencias, constituyendo parte de un paisaje tan reconocible como familiar, lleno de lenguajes y formas, diversidad y colorido. Pero si alguna parte de este gran collage multicultural ha llegado a trascender el imaginario colectivo ha sido el yelmo de Darth Vader, trasunto del aristocratismo guerrero propio del samurái. De cualquier forma, la cuestión ni mucho menos se queda en el casco, pues solo nos hallamos ante la punta de un inmenso iceberg colmado de japonismo, tal y como queda demostrado en un sinfín de convenciones relacionadas con la cultura geek.

Tradicionalmente las razones para explicarlo apuntaban al film La fortaleza escondida, cuya ascendencia sobre el texto de Lucas se considera capital aún hoy en ciertos sectores del fandom. No obstante, ya no cabe preguntarse si Star Wars proviene de una película en concreto o más bien de toda una tradición cinematográfica y estética. Japón, país conservador en algunas facetas de su cultura, fue capaz de crear a través de Akira Kurosawa un cine tan dinámico e innovador que influiría a varios directores de la generación de los 70. Uno de ellos fue George Lucas, quien a su consabida pasión por la Sci- Fi de serie B como Buck Rogers y Flash Gordon, sumó el género chambara, incluyendo todo su trasfondo filosófico, a la larga lista de cimientos que acabaron por construir su obra magna. Considerando además la relevancia y popularidad alcanzada por el género de samuráis en Europa y EE.UU., será sencillo entender por qué las estructuras narrativas, los estereotipos en personajes y sobre todo el trasfondo místico de la espada y el guerrero nipón, fueron parte esencial en el viaje que el director californiano emprendió, hace tanto, camino a las estrellas.

\section{Bibliografía}

Borrego Patrón, S. Hernández Suárez, C. "Capitalización y crisis en los salones del Manga. Organización y expansión de la cultura Otaku en Andalucía". En Gómez Aragón, A. (Coord.), Japón y Occidente, el patrimonio cultural como punto de encuentro. AEJE. 2016. Sevilla.

Bustamante, J.J. "El despertar y la felicidad en el budismo". Polis. Revista latinoamericana. N. ${ }^{\circ}$ 8. 2004. 
Cornu, P. Diccionario del Budismo. Akal. Madrid. 2004.

Hasegawa, T. The life and thougth os Shinran Shonin. Shinsu Center of America. 2015. Los Ángeles.

Kennedy, S. Zen in the Martial Arts and Star Wars. Amazon. 2010. Minneapolis.

Navarro, A.J. "Los samuráis en el cine de Akira Kurosawa". Nosferatu. Revista de Cine. $\mathrm{N}^{\circ} 44,2003$.

Freixas, R. La Fortaleza escondida. Dirigido por ... revista de cine. N ${ }^{\circ} .343,2005$.

Ortilani, B. The japanese Teatre: from shamanistic to the contemporary pluralism. Princetown University Press. 1990. Nueva Jersey.

Martínez Rico, E. La guerra de las galaxias. El mito renovado. Imágica ediciones. Toledo. 2015.

Míguez Santa Cruz, A. El fantasma en el cine japonés de posguerra. De rasgo folclórico a icono feminista. Servicio de publicaciones de la Universidad de Córdoba. 2016. Córdoba.

Plou, C. Bajo los cerezos en flor. 50 películas para conocer Japón. Ed. UOC. Barcelona. 2017.

Ramirez Serrano, G. "El Budismo como respuesta al sufrimiento". Revista Temas: Departamento de Humanidades Universidad Santo Tomás Bucaramanga. No 1. 2007.

Ritchie, D. The Films of Akira Kurosawa. California University Press.1996. Los Ángeles.

Sala Ivars, M. "Los sables japoneses y sus complementos". Revista de Museología. No 65. 2016.

Sedeño Valdellós, AM, "Cine japonés: Tradición y condicionantes creativos actuales. Una revisión histórica”. Historia y Comunicación Social. 2002. Vol. 7.

Wolf. R. "O Dharma das armas. Origem e significados da iconografía marcial encontrada no budismo". Revista de estudos da Religiao. Vol. 13. № 2. 2013.

ANTONIO MÍGUEZ SANTA CRUZ es Doctor en Cine japonés, Magíster en Cinematografía e Intervención Cultural y licenciado en Historia. Ejerce como Profesor Colaborador o Contratado de Investigación en la Universidad de Córdoba desde 2013. Su tesis doctoral fue Premio Extraordinario en Humanidades 2016, siendo considerada un estudio pionero donde se mezclaban el cine y la historia japoneses. En la vertiente divulgativa es redactor de la Iniciativa CoolJapan.es, así como de la revista de género fantástico Windumanoth. Ya en el plano académico ha publicado en varias revistas de impacto, editado libros de temática nipona y ha organizado eventos culturales de diversa índole. También forma parte del proyecto de investigación Historia y Videojuegos, de la Universidad de Murcia, además de tener en el horizonte otro relacionado con Historia y Cine en la Universidad de Cádiz.

e-mail: amiguezsantacruz@gmail.com 